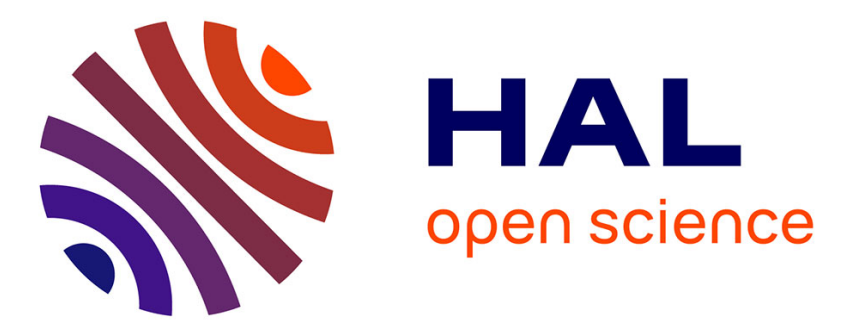

\title{
Local recurrence in rectal cancer can be predicted by histopathological factors
}

\author{
R.C. Dresen, E.E.M. Peters, H.J.T. Rutten, G.A.P. Nieuwenhuijzen, T.B.J.
} Demeyere, A.J.C. van den Brule, A.G.H. Kessels, R.G.H. Beets-Tan, J.H.J.M. van Krieken, I.D. Nagtegaal

\section{To cite this version:}

R.C. Dresen, E.E.M. Peters, H.J.T. Rutten, G.A.P. Nieuwenhuijzen, T.B.J. Demeyere, et al.. Local recurrence in rectal cancer can be predicted by histopathological factors. EJSO - European Journal of Surgical Oncology, 2009, 35 (10), pp.1071. 10.1016/j.ejso.2009.03.007 . hal-00556291

\section{HAL Id: hal-00556291 \\ https://hal.science/hal-00556291}

Submitted on 16 Jan 2011

HAL is a multi-disciplinary open access archive for the deposit and dissemination of scientific research documents, whether they are published or not. The documents may come from teaching and research institutions in France or abroad, or from public or private research centers.
L'archive ouverte pluridisciplinaire HAL, est destinée au dépôt et à la diffusion de documents scientifiques de niveau recherche, publiés ou non, émanant des établissements d'enseignement et de recherche français ou étrangers, des laboratoires publics ou privés. 


\section{Accepted Manuscript}

Title: Local recurrence in rectal cancer can be predicted by histopathological factors

Authors: R.C. Dresen, E.E.M. Peters, H.J.T. Rutten, G.A.P. Nieuwenhuïzen, T.B.J. Demeyere, A.J.C. van den Brule, A.G.H.

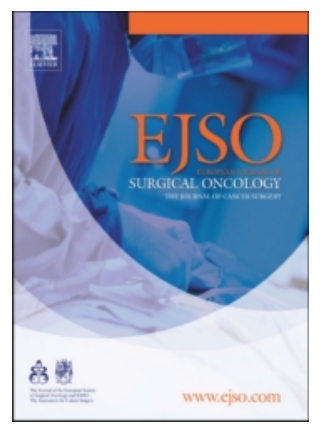

Kessels, R.G.H. Beets-Tan, J.H.J.M. van Krieken, I.D. Nagtegaal

PII: $\quad$ S0748-7983(09)00106-1

DOI: $\quad$ 10.1016/j.ejso.2009.03.007

Reference: $\quad$ YEJSO 2815

To appear in: European Journal of Surgical Oncology

Received Date: 11 November 2008

Revised Date: 17 March 2009

Accepted Date: 19 March 2009

Please cite this article as: Dresen RC, Peters EEM, Rutten HJT, Nieuwenhuijzen GAP, Demeyere TBJ, A.J.C. van den Brule, Kessels AGH, Beets-Tan RGH, van Krieken JHJM, Nagtegaal ID. Local recurrence in rectal cancer can be predicted by histopathological factors, European Journal of Surgical Oncology (2009), doi: 10.1016/j.ejso.2009.03.007

This is a PDF file of an unedited manuscript that has been accepted for publication. As a service to our customers we are providing this early version of the manuscript. The manuscript will undergo copyediting, typesetting, and review of the resulting proof before it is published in its final form. Please note that during the production process errors may be discovered which could affect the content, and all legal disclaimers that apply to the journal pertain. 


\section{Local recurrence in rectal cancer can be predicted by histopathological factors}

R.C. Dresen ${ }^{a, b}$, E.E.M. Peters ${ }^{c}$, H.J.T. Rutten ${ }^{a}$, G.A.P. Nieuwenhuijzen ${ }^{a}$, T.B.J.

Demeyere $^{d}$, A.J.C. van den Brule ${ }^{d}$, A.G.H. Kessels ${ }^{e}$, R.G.H. Beets-Tan ${ }^{b}$, J.H.J.M. van

Krieken $^{\mathrm{c}}$, I.D. Nagtegaal ${ }^{\mathrm{C}}$

${ }^{a}$ Department of Surgery, Catharina Hospital Eindhoven, Michelangelolaan 2, 5623 EJ Eindhoven, the Netherlands

${ }^{b}$ Department of Radiology, Maastricht University Medical Centre, P. Debyelaan 25, 6229 HX

Maastricht, the Netherlands

'Department of Pathology, Radboud University Medical Centre, Geert-Grooteplein-Zuid 10, 6525 GA Nijmegen, the Netherlands

${ }^{\mathrm{d} D e p a r t m e n t ~ o f ~ P a t h o l o g y, ~ P A M M ~ L a b o r a t o r i e s, ~ M i c h e l a n g e l o l a a n ~ 2, ~} 5623$ EJ Eindhoven, the Netherlands

${ }^{\text {e}}$ Department of Epidemiology, Maastricht University Medical Centre, P. Debyelaan 25, 6202 AZ

Maastricht, the Netherlands

Corresponding author

Raphaëla C. Dresen

Maastricht University Medical Centre

Postbus 5800

6202 AZ Maastricht, the Netherlands

Tel: 0031(0)43-3876910

Fax: 0031(0)43-3876909

E-mail: elleke.dresen@mumc.nl

Original article

No acknowledgements or financial disclosures 


\section{Abstract}

Aim: The main cause of local recurrence (LR) in rectal cancer is involvement of the circumferential resection margin (CRM). However, patients with a negative CRM can also develop LR, suggesting that additional factors are important for LR. The aim of this study was to identify histopathological factors predictive for the development of LR after primary rectal cancer treatment.

Methods: TxNxM0 patients treated for locally recurrent rectal cancer at the Catharina hospital from 1994 to $2006(n=92)$ were matched with a control group of patients who did not develop LR after primary rectal cancer treatment for at least 2 years $(n=185)$ based on type of neoadjuvant treatment in a 1:2 ratio. The pathology of all primary rectal cancers was reviewed. Patient, treatment and histopathological characteristics were studied in relation to the development of LR with logistic regression and Cox regression analysis.

Results: Logistic regression indicated the presence of lymphovascular invasion (LVI, OR 4.66, $\mathrm{P}<0.001$ ), extramural venous invasion (EMVI, OR 4.54, $\mathrm{P}<0.001$ ), positive CRM (OR 2.56, $\mathrm{P}=0.032)$, serosal involvement (OR 6.74, $\mathrm{P}=0.035)$ and poor differentiation (OR 2.59, $\mathrm{P}=0.012$ ) as factors with an increased risk to develop $L R$. Older age was a protective factor (OR 0.95, $\mathrm{Cl} 0.93-0.98, \mathrm{P}=0.001)$.

Conclusion: Apart from a positive CRM and serosal involvement, LVI, EMVI and poor differentiation are important independent predictive factors for the development of LR. Adjuvant therapy may be considered in the presence of these features in order to decrease the risk of a local recurrence.

\section{Key words}

rectal cancer, histopathology, local recurrence, extramural venous invasion, lymphovascular invasion. 


\section{Introduction}

The implementation of total mesorectal excision (TME) and the subsequent standardization of rectal cancer surgery have led to a significant improvement of survival and decrease of local recurrence rates (LR) ${ }^{1,2}$ However, the development of metastases and to a lesser degree local recurrence are still major problems, which will kill more than one out of three patients. From large randomized trials the most important risk factors for the development of LR are known: positive circumferential resection margin (CRM), nodal positivity and advanced T stage ${ }^{3-5}$ Improvement of preoperative imaging has resulted in early recognition of these unfavourable factors and adaptation of the treatment regimen. Neoadjuvant radiochemotherapy (RCT) has been widely accepted in case of advanced tumours with threatened circumferential margins.

But still, a number of patients without evident adverse factors develop local recurrence. In the Dutch TME study $42 \%$ of all local recurrences occurred in patients without the above mentioned risk factors (paper submitted: Patterns of local recurrence in the Dutch TME trial: bad tumor or bad surgery? M. Kusters, C.A.M. Marijnen, C.J.H. van de Velde, H.J.T. Rutten, M.J. Lahaye, J.H. Kim, R.G.H. BeetsTan, G.L. Beets ).

The current paper analyzes patients who developed local recurrence without concomitant distant metastases. The goal was to search for additional morphological changes in the primary tumour that might predict the development of local recurrence, irrespective of the more obvious tumour characteristics. Theoretically, identification of these predictors could have consequences for the treatment planning. Despite the fact that randomized studies after introduction of TME surgery are lacking, sub group analyses indicate that chemotherapy may play a role in the prevention of locally recurrent disease.$^{6-8}$ 
The histopathological markers studied were: tumour type, tumour differentiation, growth pattern, tumour budding and involvement of the serosa, nerves, lymphatic vessels, intramural and extramural veins. These markers potentially reflect the biological aggressiveness of the tumour, and they can be easily evaluated with standard pathology. They have been evaluated in colorectal cancer patients. ${ }^{9-13}$ The results showed a potential role in the prediction of recurrent (mostly distal) disease. In this relatively large cohort of patients with exclusively locally recurrent disease it is possible to evaluate the impact of these markers on local recurrence. 


\section{Materials and Methods}

\section{Patients}

In this study, primary resection specimens of patients who developed LR after primary rectal cancer treatment (cases) were compared with those of patients who did not develop LR after primary rectal cancer treatment for at least 2 years (controls). The cases consisted of patients, without metastases, treated with curative intent for locally recurrent rectal cancer at the Catharina hospital since $1994 .^{14}$ The Catharina hospital is a national referral centre for the treatment of patients with locally advanced and locally recurrent rectal cancer and thus a relatively large group of nonmetastasized patients with potentially curable locally recurrent rectal cancer was available for analysis. ${ }^{15}$ Those patients who underwent surgery with curative intent for their primary rectal cancer and who had available histopathological slides and pathology reports of the primary rectal resection specimen were included in this study (92 out of 147). The case-control matching was done in a 1:2 ratio based on neoadjuvant treatment schemes (either no neoadjuvant treatment or a short course of radiotherapy of $5 \times 5$ Gray (Gy) or a long course of radio(chemo)therapy of 50.4 Gy).

Control patients were retrieved from two different patient populations in the same time period as the cases. Those who received no or 5x5 Gy neoadjuvant therapy were used from the Dutch TME trial, a large multicenter trial comparing patients with or without neoadjuvant radiotherapy before standardized TME surgery. ${ }^{16}$ Those who received 50.4 Gy as neoadjuvant treatment were used from a population of patients with locally advanced rectal cancer (LARC) referred to and treated at the Catharina hospital since $1994 .{ }^{17}$ From both populations, consecutive patients were included 
until a 1:2 case-control ratio was achieved (Table 1). Approval of this study was given by the institutional review committee and informed consent was obtained.

\section{Neoadjuvant treatment}

Neoadjuvant treatment was administered according to the national guidelines at that time or according to randomization in the Dutch TME trial. ${ }^{16}$ Patients with primarily resectable cancer received either no neoadjuvant therapy or a short course of 5x5 Gy in one week. Patients with LARC were treated preoperatively with a long course of radio(chemo)therapy. Radiotherapy consisted of 50.4 Gy, 5 times a week in 28 fractions of $1.8 \mathrm{~Gy}$. In $40 \%$ of the patients, the radiotherapy was combined with chemotherapy consisting $5-\mathrm{FU}\left(350 \mathrm{mg} / \mathrm{m}^{2}\right)$ plus leucovorin $\left(20 \mathrm{mg} / \mathrm{m}^{2}\right)$ in week 1 and 5 or capecitabine $\left(2 \times 825 \mathrm{mg} / \mathrm{m}^{2} / \mathrm{d}\right)$ plus oxaliplatin $\left(50 \mathrm{mg} / \mathrm{m}^{2} /\right.$ week $)$.

\section{Surgery}

All patients underwent surgery with curative intent either immediately (without neoadjuvant therapy), or one week after 5x5 Gy or 6-8 weeks after long course radio(chemo)therapy. TME trial patients underwent the standardized surgery according to the TME principle with excision of both the rectum and the surrounding mesorectal envelope along the mesorectal fascia. ${ }^{16}$ In earlier patients the significance of the mesorectal fascia may not have been recognized and they underwent a more classical resection of the rectal tumour. LARC patients underwent either TME or a more extensive resection, depending on the extent of tumour growth. As cases and control patients were retrieved from the same time period, no difference in surgical techniques was found between the 2 groups. 


\section{Histopathology}

The primary rectal cancer resection specimens were evaluated according to the protocol of Quirke and Dixon. ${ }^{18}$ The following histopathological factors were assessed: invasion depth (T classification), nodal status ( $\mathrm{N}$ classification), circumferential resection margin (CRM) status, tumour type, tumour differentiation, growth pattern, tumour budding and involvement of the serosa, neural tissue, lymphatic vessels, intramural and extramural veins. Serosal involvement could be present when the tumour was located in the higher part of the rectum (between sacral promontory and cavum douglasi), which is partially covered by serosa. The assessment was performed on haematoxylin and eosin stained slides of the primary rectal cancer specimen by two observers in consensus reading. In case of difficulty or disagreement an expert gastrointestinal pathologist was consulted. The observers were blinded to patients' outcome. T classification and $\mathrm{N}$ classification were assessed according to UICC 1997 (TNM 5th edition). Classification of tumours was performed using the WHO guidelines; a tumour was scored as adenocarcinoma, adenocarcinoma with a mucinous component $(<50 \%)$ or mucinous carcinoma (mucinous component $\geq 50 \%$ ). Tumour differentiation was scored as well/ moderately versus poorly differentiated based on the area with the least differentiated part of the tumour (not the invasive front). Growth patterns were assessed as circumscribed or infiltrating. However, in patients who received 50.4 Gy this factor was not assessed, because tumour regression interferes with growth pattern. Lymphovascular invasion (LVI) was defined as tumour within an endothelial lined space either in the bowel wall or in the mesorectal fat. Venous invasion was defined as tumour within a space lined by endothelial cells and smooth muscle or elastic fibres. It can be divided into either intramural venous invasion (IMVI) or extramural venous invasion (EMVI: venous 
invasion present outside the muscularis propria layer within the surrounding mesorectal fat). In addition, an adjacent arterial structure had to be present. Tumour budding was considered to be present when small tumour cell clusters of fewer than 5 undifferentiated tumour cells were seen at the invasive front.

\section{Statistical analysis}

To compare proportions between recurrent group and control group Chi-Square and Fisher Exact tests were performed. To predict the development of LR by histopathological, patient (age, sex) and treatment (type of surgery) related variables logistic regression analysis was performed. Both enter method and forward step (variable entered if $\mathrm{P}<0.05$ ) method analyses were used. The results were adjusted for the matching based on type of neoadjuvant treatment. After creation of the multivariate model the predicted probabilities were saved. With these probabilities a ROC curve was constructed in order to assess the accuracy of the model for the prediction of the development of a local recurrence.

In the recurrent group, local recurrence free interval (LRFI) was calculated from the primary resection date until the local recurrence resection date. Local control (LC) curves were constructed using the Kaplan-Meier method. Cox proportional hazard regression was performed to correlate the histopathological, patient and treatment related factors with LC in a multivariate manner. A P-value of $\leq 0.05$ (two-sided) was considered as statistically significant. Statistical analyses were performed using the SPSS statistical software program (SPSS ${ }^{\circledR}$ for Windows Release 15.0, SPSS Inc, Chicago, IL, USA). 


\section{Results}

Patient and treatment characteristics

In total, 277 patients (163 men, 104 women) were included in this study. Median age was 62 (range 33-89). Patients received either no neoadjuvant radiotherapy $(n=129)$, $5 \times 5 \mathrm{~Gy}(\mathrm{n}=66)$ or a long course of $50.4 \mathrm{~Gy}(\mathrm{n}=82)$. This was followed by a low anterior resection (LAR) in 184 patients or an abdominoperineal resection (APR) in 93 patients. After surgery, 29 patients had a positive CRM. Ninety-two patients developed LR after primary treatment. Median interval between primary and recurrence surgery was 27.5 months, range 3-156 months. Patient and treatment characteristics categorized according to the recurrent and control group are listed in Table 1. Median follow-up of the recurrent group was 58 months (range 13-289), for the control group it was 66 months (range 24-200).

Histopathological factors in recurrent versus control group (Table 1) In patients who developed LR after primary rectal cancer treatment, a positive CRM was found in $16.3 \%$ versus $7.6 \%$ in the control group $(P=0.036)$. Furthermore, serosal involvement was present in $9.9 \%$ versus $1.1 \%$ in the control patients $(P=0.001)$. Patients who developed $L R$, underwent a low anterior resection more often $(77.2$ vs. $61.1 \%, P=0.010)$ and had more tumours with a poor differentiation ( 23.9 vs. $13.3 \%, P=0.041$ ) than control patients. Additionally, lymphovascular invasion ( $\mathrm{LVI})$ and extramural venous invasion (EMVI) were found more often in the recurrent group than in the control group $(40.2 \%$ versus $11.4 \%$ and $41.3 \%$ versus $13.0 \%$ respectively, both $\mathrm{P}<0.001)$.

Logistic regression analysis 
The whole population was analyzed in a univariate and multivariate manner with adjustment for neoadjuvant treatment (Table 2). Multivariate analysis (enter method) revealed LVI (Figure 1A, OR 5.26), EMVI (Figure 1B, OR 4.79), positive CRM (OR 2.64) and a tumour with a mucinous component (OR 3.00) as independent parameters with an increased risk for a local recurrence. Poor differentiation reached borderline significance (OR 2.67, $\mathrm{P}=0.051)$. Patients with an older age and positive nodal status had a significantly lower risk for the development of a potentially resectable LR (OR 0.94 and 0.42 respectively). The area under the ROC curve of the predicted probabilities was 0.83 (95\% confidence interval (Cl) $0.78-0.88$ ).

The forward stepwise (LR) multivariate logistic regression analysis indicated the presence of LVI (OR 4.66, 95\% Cl 2.34-9.25, P<0.001), EMVI (OR 4.54, 95\% Cl 2.30-8.95, $\mathrm{P}<0.001$ ), positive CRM (OR 2.56, 95\% Cl 1.08-6.07, $\mathrm{P}=0.032$ ), serosal involvement (OR 6.74, 95\% Cl 1.15-39.6, $\mathrm{P}=0.035)$ and poor differentiation (OR 2.59, $95 \% \mathrm{Cl} 1.24-5.42, \mathrm{P}=0.012$ ) as factors with an increased risk to develop LR. Eightytwo percent of patients in the recurrent group had either one of these factors. Older age was a protective factor (OR $0.95,95 \% \mathrm{Cl} 0.93-0.98, \mathrm{P}=0.001)$. The same independent factors were found in CRM negative patients ( $n=248$ ): LVI (OR 4.27, $\mathrm{P}<0.001$ ), EMVI (OR 4.91, $\mathrm{P}<0.001$ ), serosal involvement (OR 6.31, $\mathrm{P}=0.040$ ), poor differentiation ( $O R$ 3.13, $P=0.005)$ and older age (OR 0.96, $P=0.008)$. When taking only lymph node negative (N0) patients ( $\mathrm{n}=201$ ) into account, those with LVI or EMVI had an even higher risk on LR (OR 7.06 and 8.56 respectively, $\mathrm{P}<0.001$ ).

Furthermore, a poor differentiation had a negative impact on outcome (OR 2.61, $P=0.044)$.

Last paragraph of Results was removed. 


\section{Discussion}

Most important histopathological factors

The present study investigated the predictive value of several histopathological factors for the development of LR after primary rectal cancer treatment by comparing cases with controls. We found that a positive CRM, serosal involvement, LVI, EMVI and poor differentiation were the most important independent factors with an increased risk on LR. As has been frequently observed, ${ }^{4}$ positive CRM is key factor in the development of LR. However, with the use of improved surgical techniques a positive CRM will occur less and less often and as a consequence tumour-related factors may become more important. By using the case-control approach and patients with local recurrence only without distant metastases as point of departure, CRM, although still significant, became a less important prognostic factor in our study. In accordance to our findings, other authors have also shown that serosal involvement ${ }^{19}$ and poor differentiation ${ }^{9,20}$ have a negative influence on prognosis. The two most important factors in our analysis, also in CRM negative patients, were LVI and EMVI. LVI is regarded as a precursor of tumour growth in lymph nodes and many studies have demonstrated its prognostic significance. ${ }^{21}$ However, some studies were not able to prove its independent impact on LR rate and survival. ${ }^{12,13}$ EMVI is regarded as early haematogenous cancer spread and has mainly been correlated with metastases ${ }^{22,23}$ and survival. ${ }^{12,20}$ In our study, however, we proved that EMVI was also strongly correlated with LR (OR 4.54, $\mathrm{P}<0.001)$.

\section{Variation in incidence of EMVI}

The incidence of EMVI in our study was $22 \%$ (43\% in recurrent and $13 \%$ in control group). The incidence described in the literature varies widely, ranging from $10-$ 
$90 \%{ }^{23}$ Quirke and Morris stated that on average a careful pathologist would find an EMVI in around $30 \%$ of the patients ${ }^{24}$ as was the case in our study. There are several reasons for the differences in incidence and prognosis. Intra- and extramural venous invasion are sometimes grouped together, ${ }^{11}$ as are lymphatic and blood vessel invasion. ${ }^{10}$ Moreover, interobserver variability may be substantial, ${ }^{19}$ because of infiltration/ destruction of vessel wall. Some authors advocate the use of special elastic tissue stains for the assessment of venous invasion. ${ }^{23,25}$ However, there is no agreement, because this is labour intensive, time consuming, relatively expensive and results are contradictory. ${ }^{10,19}$ Incidence of venous invasion also depends on sampling and assessment of the resection specimen. ${ }^{26,27}$

\section{Selected population}

In our study, patients with positive lymph nodes had a lower risk to develop LR on multivariate analysis (enter method). At first sight, this may appear strange. However, our LR patients were sent to our hospital for recurrence treatment with curative intent (as can be indicated by the relatively good prognosis after surgery) ${ }^{14}$ and we assume that hence there is a selection bias for patients with curable LR. Despite the presence of positive lymph nodes in the primary tumours of our patients, they might have a favourable prognosis based on other (clinical) parameters, and thus in this selected group lymph node positivity is probably not a sign of very advanced, and thus incurable disease. Similar argumentation can be used in cases treated with APR. On univariate analysis, they were less likely to develop a LR (data not shown), although several studies suggest that these patients generally have a poorer prognosis than patients who underwent a LAR. ${ }^{28,29}$ 


\section{Limitation of the study}

The retrospective nature of our study introduced some bias, because although all available haematoxylin and eosin slides were thoroughly reviewed, the selection of the slides was dependent on the accuracy of specimen sampling by the initial pathologists. However, an area under the ROC curve of the predicted probabilities of 0.83 indicates a high accuracy of our model for the prediction of the development of LR. In addition, a case-control design limits the generalization of our results. However, since the improvements in treatment have minimized the occurrence of LR, large patient populations are unavailable.

\section{Adjuvant chemotherapy}

The role of adjuvant chemotherapy is still unclear. No recent randomized studies have been performed and those that have been are of older date before the introduction of TME surgery. ${ }^{23}$ However, the EORTC study as well as the Quasar study indicate that in subgroups of patients adjuvant chemotherapy might be effective

to reduce local recurrences. ${ }^{6-8}$ We believe that administration of adjuvant chemotherapy in patients with high risk factors (in our study EMVI, LVI, poor differentiation, positive CRM and serosal involvement) might be justified. In patients who normally do not receive adjuvant treatment (N0 patients) we found that the negative impact of both EMVI and LVI was even more pronounced. These factors might be important for the selection of UICC stage II patients who will benefit from adjuvant therapy. The QUASAR collaborative workgroup ${ }^{8}$ found that adjuvant treatment in all stage II colorectal cancer patients, irrespective of the presence of poor prognostic factors, improved survival and decreased both overall and local 
recurrence rates significantly. However, absolute improvement in survival was only $3.6 \%$. Patients selected based on poor prognostic factors might benefit more from adjuvant treatment. Furthermore, by making those careful selections and withholding adjuvant chemotherapy in low risk patients we can prevent unnecessary morbidity. In addition to more selective application of adjuvant treatment, follow-up regimens might be differentiated, providing more intensive follow-up in high risk patients and less radical follow-up in low risk patients. This will make the treatment of rectal cancer more individualized and more cost-effective.

\section{Conclusion}

In conclusion, positive CRM, serosal involvement, EMVI, LVI and poor differentiation are important independent factors predictive for the development of LR after primary rectal cancer treatment. These factors should always be reported in the pathology report and patients with these factors might be treated with adjuvant chemotherapy and followed-up more closely in order to prevent the occurrence of LR. In future, molecular markers may help us further to identify those patients with a high risk of developing local recurrence.

\section{Conflict of interest}

The authors state that they have no conflict of interest. 
References

1. Heald RJ, Husband EM, Ryall RD. The mesorectum in rectal cancer surgery-the clue to pelvic recurrence? Br J Surg 1982;69:613-616.

2. Kapiteijn $\mathrm{E}$, Putter $\mathrm{H}$, van $\mathrm{d}, \mathrm{V}$. Impact of the introduction and training of total mesorectal excision on recurrence and survival in rectal cancer in The Netherlands. Br J Surg 2002;89:1142-1149.

3. Moran MR, James EC, Rothenberger DA, Goldberg SM. Prognostic value of positive lymph nodes in rectal cancer. Dis Colon Rectum 1992;35:579-581.

4. Nagtegaal ID, Quirke $P$. What is the role for the circumferential margin in the modern treatment of rectal cancer? J Clin Oncol 2008;26:303-312.

5. Quirke P, Durdey P, Dixon MF, Williams NS. Local recurrence of rectal adenocarcinoma due to inadequate surgical resection. Histopathological study of lateral tumour spread and surgical excision. Lancet 1986;2:996-999.

6. Bosset JF, Collette L, Calais G, et al. Chemotherapy with preoperative radiotherapy in rectal cancer. N Engl J Med 2006;355:1114-1123.

7. Collette L, Bosset JF, den Dulk M, et al. Patients with curative resection of cT3-4 rectal cancer after preoperative radiotherapy or radiochemotherapy: does anybody benefit from adjuvant fluorouracil-based chemotherapy? A trial of the European Organisation for Research and Treatment of Cancer Radiation Oncology Group. J Clin Oncol 2007;25:4379-4386.

8. Quasar Collaborative Group, Gray R, Barnwell J, et al. Adjuvant chemotherapy versus observation in patients with colorectal cancer: a randomised study. Lancet 2007;370:2020-2029.

9. Compton CC. Pathology report in colon cancer: what is prognostically important? Dig Dis 1999;17:67-79.

10. Compton CC, Fielding LP, Burgart LJ, et al. Prognostic factors in colorectal cancer. College of American Pathologists Consensus Statement 1999. Arch Pathol Lab Med 2000;124:979-994.

11. Meguerditchian AN, Bairati I, Lagace R, Harel F, Kibrite A. Prognostic significance of lymphovascular invasion in surgically cured rectal carcinoma. Am J Surg 2005;189:707-713.

12. Morris M, Platell C, de Boer B, McCaul K, lacopetta B. Population-based study of prognostic factors in stage II colonic cancer. Br J Surg 2006;93:866-871.

13. Ptok $H$, Meyer $F$, Steinert $R$, et al. No prognostic impact of isolated lymphovascular invasion after radical resection of rectal cancer--results of a multicenter observational study. Int J Colorectal Dis 2007;22:749-756.

14. Dresen RC, Gosens MJ, Martijn H, et al. Radical resection after IORTcontaining multimodality treatment is the most important determinant for 
outcome in patients treated for locally recurrent rectal cancer. Ann Surg Oncol 2008;15:1937-1947.

15. Rutten HJ, Mannaerts $\mathrm{GH}$, Martijn $\mathrm{H}$, Wiggers $\mathrm{T}$. Intraoperative radiotherapy for locally recurrent rectal cancer in The Netherlands. Eur J Surg Oncol 2000;26 Suppl A:S16-S20.

16. Kapiteijn E, Marijnen CA, Nagtegaal ID, et al. Preoperative radiotherapy combined with total mesorectal excision for resectable rectal cancer. $N$ Engl J Med 2001;345:638-646.

17. Gosens MJ, Klaassen RA, Tan-Go I, et al. Circumferential margin involvement is the crucial prognostic factor after multimodality treatment in patients with locally advanced rectal carcinoma. Clin Cancer Res 2007;13:6617-6623.

18. Quirke P, Dixon MF. The prediction of local recurrence in rectal adenocarcinoma by histopathological examination. Int $\mathrm{J}$ Colorectal Dis 1988;3:127-131.

19. Stewart CJ, Morris M, de BB, lacopetta B. Identification of serosal invasion and extramural venous invasion on review of Dukes' stage B colonic carcinomas and correlation with survival. Histopathology 2007;51:372-378.

20. Freedman LS, Macaskill $P$, Smith AN. Multivariate analysis of prognostic factors for operable rectal cancer. Lancet 1984;2:733-736.

21. Minsky BD, Mies C, Rich TA, Recht A. Lymphatic vessel invasion is an independent prognostic factor for survival in colorectal cancer. Int J Radiat Oncol Biol Phys 1989;17:311-318.

22. Ouchi K, Sugawara T, Ono H, et al. Histologic features and clinical significance of venous invasion in colorectal carcinoma with hepatic metastasis. Cancer 1996;78:2313-2317.

23. Sternberg A, Amar M, Alfici R, Groisman G. Conclusions from a study of venous invasion in stage IV colorectal adenocarcinoma. J Clin Pathol 2002;55:17-21.

24. Quirke P, Morris E. Reporting colorectal cancer. Histopathology 2007;50:103112.

25. Vass DG, Ainsworth R, Anderson JH, Murray D, Foulis AK. The value of an elastic tissue stain in detecting venous invasion in colorectal cancer. J Clin Pathol 2004;57:769-772.

26. Dirschmid K, Lang A, Mathis G, Haid A, Hansen M. Incidence of extramural venous invasion in colorectal carcinoma: findings with a new technique. Hum Pathol 1996;27:1227-1230.

27. Ludeman L., Shepherd N.A. Macroscopic assessment and dissection of colorectal cancer resection specimens. Current Diagnostic Pathology 2006;12:220-230. 
28. Heald RJ, Moran BJ, Ryall RD, Sexton R, MacFarlane JK. Rectal cancer: the Basingstoke experience of total mesorectal excision, 1978-1997. Arch Surg 1998;133:894-899.

29. Peeters KC, Marijnen CA, Nagtegaal ID, et al. The TME trial after a median follow-up of 6 years: increased local control but no survival benefit in irradiated patients with resectable rectal carcinoma. Ann Surg 2007;246:693-701. 
Figure legends

Figure 1A.

Lymphovacular invasion. Tumor invasion of a lymphatic vessel. $\mathrm{T}=$ tumor, arrow $=$ lymphatic valve. (Hematoxylin and eosin stain; original magnification $x$ 10.)

\section{Figure 1B.}

Extramural venous invasion. Tumor invasion of a vein in the mesorectal fat. $\mathrm{T}=$ tumor, arrow $=$ artery, arrowhead $=$ venous wall. $($ Hematoxylin and eosin stain; original magnification $\times 5$.) 


\begin{tabular}{|c|c|c|}
\hline & $\begin{array}{c}\text { Recurrent } \\
(n=92)\end{array}$ & $\begin{array}{l}\text { Control } \\
(n=185)\end{array}$ \\
\hline \multicolumn{3}{|l|}{ UICC-stage (TNM 5) } \\
\hline - & 12 & 59 \\
\hline II & 52 & 78 \\
\hline III & 28 & 48 \\
\hline \multicolumn{3}{|l|}{ T-classification } \\
\hline 1 & 1 & 13 \\
\hline 2 & 16 & 56 \\
\hline 3 & 62 & 108 \\
\hline 4 & 13 & 8 \\
\hline \multicolumn{3}{|l|}{ N-classification } \\
\hline NO & 64 & 137 \\
\hline $\mathrm{N}+$ & 28 & 48 \\
\hline \multicolumn{3}{|l|}{ Tumor type } \\
\hline Adenocarcinoma & 65 & 147 \\
\hline Mucinous component & 17 & 23 \\
\hline Mucinous & 10 & 15 \\
\hline \multicolumn{3}{|l|}{ Differentiation } \\
\hline Well/ Moderate & 70 & 160 \\
\hline Poor & 22 & 25 \\
\hline \multicolumn{3}{|l|}{ Growth pattern ${ }^{a}$} \\
\hline Circumscribed & 53 & 105 \\
\hline Diffuse & 13 & 24 \\
\hline Perineural Invasion & 9 & 11 \\
\hline LVI & 37 & 21 \\
\hline EMVI & 38 & 24 \\
\hline IMVI & 13 & 15 \\
\hline Tumor budding & 23 & 34 \\
\hline \multicolumn{3}{|l|}{ CRM } \\
\hline Negative & 77 & 171 \\
\hline Positive & 15 & 14 \\
\hline \multicolumn{3}{|l|}{ Serosa } \\
\hline Negative & 83 & 183 \\
\hline Positive & 9 & 2 \\
\hline \multicolumn{3}{|c|}{$\begin{array}{l}\text { Values in parentheses are percentages unless otherwise specified. LVI, } \\
\text { lymphovascular invasion; EMVI, extramural venous invasion; IMVI, intramural } \\
\text { venous invasion; CRM, circumferential resection margin. anot assessed in } \\
\text { patients who received long course neoadjuvant therapy. }\end{array}$} \\
\hline
\end{tabular}


TABLE 2. Logistic regression analysis for the whole population $(n=277)$ of patient, treatment and tumor related factors predictive for a local recurrence

\begin{tabular}{|c|c|c|c|c|}
\hline & \multicolumn{2}{|c|}{ Univariate analysis } & \multicolumn{2}{|c|}{ Multivariate analysis } \\
\hline & OR & $95 \% \mathrm{Cl}$ & OR & $95 \% \mathrm{Cl}$ \\
\hline \multicolumn{5}{|l|}{ T-stage } \\
\hline 1 & 1.00 & & 1.00 & \\
\hline 2 & 4.02 & $0.49-33.1$ & 1.17 & $0.13-10.6$ \\
\hline 3 & 8.44 & $1.07-66.7 *$ & 2.19 & $0.25-18.9$ \\
\hline 4 & 25.0 & $2.67-234^{* *}$ & 4.46 & $0.34-59.3$ \\
\hline \multicolumn{5}{|l|}{$\mathrm{N}$-stage } \\
\hline NO & 1.00 & & 1.00 & \\
\hline $\mathrm{N}+$ & 1.22 & $0.70-2.11$ & 0.43 & $0.20-0.93 *$ \\
\hline \multicolumn{5}{|l|}{ Tumor type } \\
\hline Adenocarcinoma & 1.00 & & 1.00 & \\
\hline Mucinous component & 1.67 & $0.84-3.35$ & 3.00 & $1.26-7.11 *$ \\
\hline Mucinous & 1.56 & $0.66-3.70$ & 1.91 & $0.51-7.12$ \\
\hline \multicolumn{5}{|l|}{ Differentiation } \\
\hline Well/ Moderate & 1.00 & & 1.00 & \\
\hline Poor & 2.10 & $1.10-4.03 *$ & 2.67 & $1.00-7.18$ \\
\hline Perineural invasion & 1.74 & $0.69-4.37$ & 1.80 & $0.56-5.81$ \\
\hline LVI & 5.30 & $2.86-9.83^{* * *}$ & 5.26 & $2.43-11.4^{* * *}$ \\
\hline EMVI & 4.73 & $2.60-8.62 * * *$ & 4.79 & $2.20-10.5^{* * *}$ \\
\hline IMVI & 1.86 & $0.84-4.11$ & 1.87 & $0.69-5.08$ \\
\hline Tumor budding & 1.49 & $0.81-2.75$ & 1.39 & $0.63-3.06$ \\
\hline \multicolumn{5}{|l|}{ CRM } \\
\hline Negative & 1.00 & & 1.00 & \\
\hline Positive & 2.49 & $1.13-5.47^{*}$ & 2.64 & $1.02-6.80 *$ \\
\hline \multicolumn{5}{|l|}{ Serosa } \\
\hline Negative & 1.00 & & 1.00 & \\
\hline Positive & 10.2 & $2.15-48.8^{* *}$ & 2.76 & $0.29-26.6$ \\
\hline
\end{tabular}




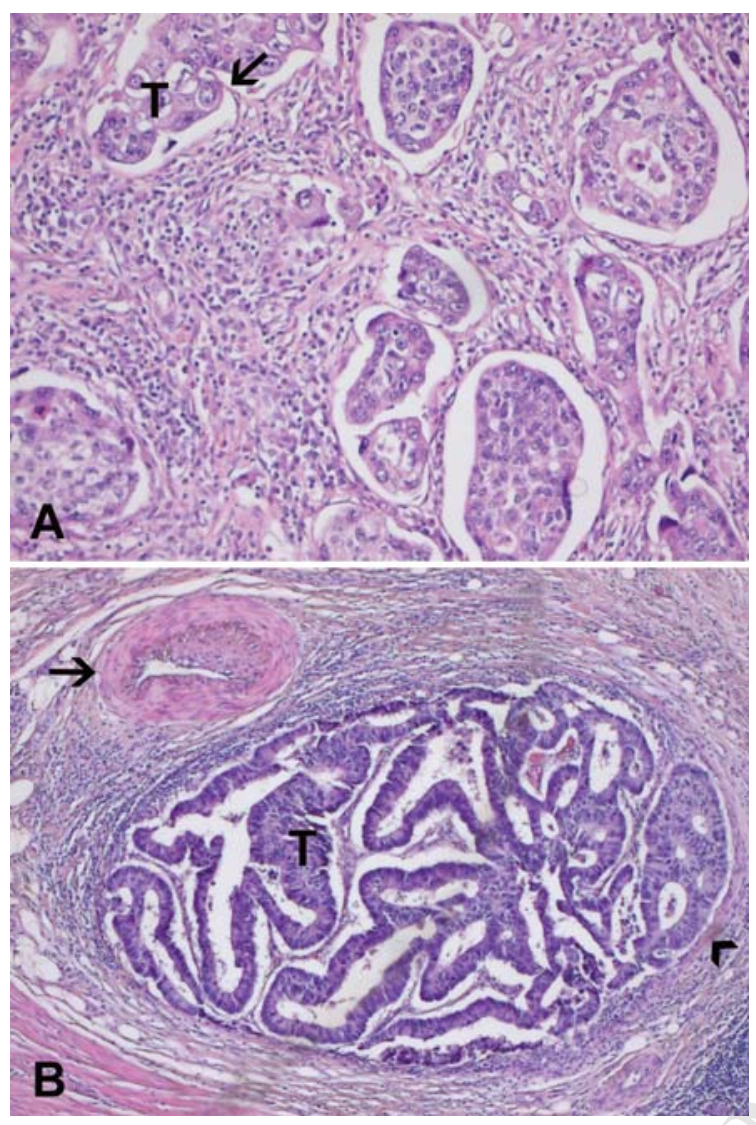

